\title{
ACESSIBILIDADE A MOBILIÁRIO E EQUIPAMENTOS DE TERMINAIS AEROPORTUÁRIOS: COMPARAÇÕES ENTRE A LEGISLAÇÃO E A EXPERIÊNCIA DO USUÁRIO COM DEFICIÊNCIA VISUAL
}

\author{
CAVALCANTE, Erika Pinheiro Gomes (1); \\ DUARTE, Cristiane Rose de Siqueira (2); \\ COHEN, Regina (3) \\ (1) Universidade Federal do Ceará (UFC), Mestra em arquitetura \\ e-mail:erika cavalcante@hotmail.com \\ (2) Universidade Federal do Rio de Janeiro (UFRJ), Pós-doutora em arquitetura \\ e-mail: crsduarte@gmail.com \\ (3) Universidade Federal do Rio de Janeiro (UFRJ), Pós-doutora em arquitetura \\ e-mail: arquitetareginacohen@gmail.com
}

\begin{abstract}
RESUMO
Este artigo trata da acessibilidade nos terminais aeroportuários focando, mais especificamente, na experiência da pessoa com deficiência visual. Tendo como estudo de caso o Aeroporto Santos Dumont, no Rio de Janeiro, a pesquisa buscou avaliar se as expectativas das pessoas cegas e com baixa visão correspondem à legislação atual. Neste artigo focamos o caso dos equipamentos, mobiliários e layout. As metodologias empregadas foram: revisão bibliográfica, entrevistas, poema dos desejos e observação participante. Os resultados da pesquisa revelam diversas contradições entre as demandas do usuário e a legislação e evidenciam a necessidade de se prosseguir com pesquisas referentes à temática.
\end{abstract}

Palavras chave: Acessibilidade, Deficiência Visual, aeroportos, legislação.

\begin{abstract}
This present article deals with accessibility at airport terminals, specifically focusing on the experience of visually impaired people. Having as a case study Santos Dumont Airport, in Rio de Janeiro, the research sought to assess whether the expectations of blind and visually impaired people meet current legislation. In this article we focus on equipment, furniture and layout. As a methodology, the research considered: interviews, wish poem and participant observation. Results of the study reveal several contradictions between users' demands and the legislation content and highlight the need to continue with research on the subject.
\end{abstract}

Keywords: Accessibility, Visual Impairment, Airports, Legislation. 


\section{INTRODUÇÃO}

Apesar do empenho da Empresa Brasileira de Infraestrutura Aeroportuária (Infraero) ${ }^{1}$ em atender a legislação ${ }^{2}$ referente à acessibilidade em seus terminais de passageiros ${ }^{3}$ (TPSs), a inclusão das pessoas com deficiência visual $(P c D V s)^{4}$,com autonomia e segurança, nesses espaços ainda é ineficaz. A deficiência visual ${ }^{5}$, recorte social deste artigo, compreende indivíduos cegos e com baixa visão (ABNT, 2016; VENTURINI, 2009; ABNT, 2005). As PcDVs ainda dependem, recorrentemente, do atendimento assistido nos aeroportos.

Os aeroportos são polos integradores que influenciam o desenvolvimento de localidades, a expansão e a interação de mercados e pessoas, o dinamismo e a internacionalização de economias, entre outros aspectos indispensáveis ao atual contexto da globalização. $O$ terminal de passageiros, recorte espacial deste trabalho, se trata de uma infraestrutura surgida no final da década de 1920 para atender, com conforto e segurança, ao processamento de passageiros e bagagens (YOUNG; WELLS, 2014).

As tendências contemporâneas exigem dos terminais uma nova postura operacional, comercial, social e cultural (CAVALCANTE; DUARTE; COHEN, 2016). Diferente das edificações simples de outrora, precisam compatibilizar procedimentos operacionais e não operacionais, gestões múltiplas, atividades, tecnologias e fluxos dinâmicos e complexos, considerando ainda as expectativas dos passageiros. Compreendendo-se sua natureza singular, é fácil entender que implementar a acessibilidade nos TPSs não é igual a implementa-la em qualquer outra edificação. Boa parte da legislação, contudo, é direcionada às edificações em geral ${ }^{6}$, não se referindo às especificidades aeroportuárias.

Em 2014 o Aeroporto Santos Dumont (SDU), nosso estudo de caso, foi apontado pela Secretaria Municipal da Pessoa com Deficiência como o modelo de acessibilidade carioca. Foi o único local, entre os 250 vistoriados, a merecer a premiação máxima: o Selo Diamante de Acessibilidade. A Informação Técnica no 121/2014 do Ministério Público do Rio de Janeiro (MPRJ), atestou que o terminal dispunha de boas condições de acessibilidade.

No entanto, em nossa pesquisa, questionamo-nos acerca da percepção da PcDV com relação a essa acessibilidade. Perguntamo-nos se, mesmo que toda a legislação referente à acessibilidade fosse cumprida, a experiência nos terminais de passageiros da Infraero seria realmente satisfatória, oferecendo autonomia para a pessoa com deficiência visual.

\section{A PESQUISA}

\subsection{Metodologia}

Após uma densa revisão bibliográfica - que incluiu não apenas os estudos sobre a deficiência visual e a acessibilidade mas, também, a questão do planejamento, gestão e arquitetura aeroportuários; os documentos oficiais e legislações pertinentes; Selo de Acessibilidade da SMPD, entre outros assuntos - verificamos que havia lacunas resultantes da singularidade do tema. De fato, ainda há pouca literatura acerca da acessibilidade da pessoa com deficiência visual nos terminais aeroportuários, bem como sobre sua experiência nesses ambientes.

\footnotetext{
${ }^{1}$ A Infraero- maior empresa de administração aeroportuária do país- é uma empresa pública (BRASIL, 1972).

${ }^{2}$ De início, esclarecemos que, neste trabalho, legislação refere-se a leis, decretos, normas validadas por força de lei, normas técnicas, entre outros.

${ }^{3}$ Neste artigo, o termo "terminal" refere-se especificamente ao terminal de passageiros (TPS) da aviação civil.

${ }^{4} \mathrm{O}$ termo Pessoa com Deficiência Visual será representado, neste trabalho, pela sigla PcDV

${ }^{5} \mathrm{~A}$ escolha da deficiência visual se refere apenas ao estabelecimento de um recorte necessário ao desenvolvimento do trabalho. Defendemos que todos os tipos de deficiência devem ser tratados com relevância.

${ }^{6}$ À exemplo da NBR no 9050/15, que regulamenta, de forma geral a acessibilidade nas edificações, mobiliário, espaços e equipamentos urbanos, em área urbana ou rural.
} 
A pesquisa realizou entrevistas abertas e, posteriormente, semi-estruturadas. As entrevistas semi-estruturadas foram aplicadas dentro do terminal do Aeroporto Santos Dumont.

Outra ferramenta utilizada na pesquisa foi o poema dos desejos, a fim de avaliar o ambiente construído. Conforme Brasileiro et al. (2004), a ferramenta, desenvolvida por Henry Sanoff ${ }^{7}$, objetiva captar os desejos de seus respondentes e permite, por meio da comparação das múltiplas respostas, compreender o perfil da comunidade pesquisada em relação a seus anseios e demandas. Assim, colocamos aos entrevistados com deficiência visual a seguinte questão: "Como seria o aeroporto dos seus 'sonhos"'?

A abordagem desta pesquisa foi qualitativa e se propôs a "compreender os fenômenos segundo a perspectiva dos sujeitos, ou seja, dos participantes da situação em estudos" (GODOY, 1995, p. 58). Foram ouvidas, ao todo, 23 pessoas, sendo: 20 PcDVs (14 cegos e 06 com baixa visão), 01 acompanhante experiente de um indivíduo cego, 01 professora de Orientação e Mobilidade do Instituto Benjamim Constant e 01 assessor da Infraero.

\subsection{Análise de mobiliários e equipamentos do terminal aeroportuário}

A pesquisa que está na base deste artigo foi desenvolvida com base na divisão em categorias $^{8}$ identificadas no uso dos terminais pelas PcDVs: mobiliários e equipamentos; orientação e mobilidade e, por fim, atendimento. Devido às limitações de espaço deste texto, será exposta aqui unicamente a categoria referente a Layout, mobiliário e equipamentos.

Tomando como exemplo alguns dos equipamentos e mobiliários organizados no âmbito da administração dos terminais aeroportuários (Infraero), foram analisados: balcões de informações, esteiras para restituição de bagagens, carrinhos de bagagem, escadas fixas e rolantes, elevadores, telas com Sistema Informativo de Voos (SIV), pontes de embarque e desembarque, sistema de som, sinalização do TPS, sanitários, sistemas de climatização, entre outros (YOUNG; WELLS, 2014; INFRAERO, 2013). A análise abaixo tece resumidamente algumas considerações obtidas durante o confronto desses equipamentos com a experiência do usuário com deficiência visual.

a) Serviço de informação de voos (SIV): Este serviço informa os usuários sobre pousos e decolagens. Constatamos que tal sistema é inservível para a PcDV: não há telas SIV adaptadas e as informações sonoras são restritas às salas de embarque e desembarque, locais que, inclusive, são restritos a passageiros. Como disse um de nossos informantes:

Por exemplo, aqui [saguão] a gente não ouve nada sobre movimentação [de voos]. Eles alegam que tiraram porque havia muita poluição sonora.[...]. Para nós, é um referencial importante. [...]. É, vocês têm a tela, não é isso? Então, nós não temos. Isso aí é um tratamento desigual. [...]. Vocês têm tudo à disposição: as informações todas, avião que tá pra chegar, não sei o que do aeroporto, os horários e tal. Tudo bem, está tudo disponível para vocês, agora, pra gente, não! (R20)

Pelo relato do respondente $\mathrm{R} 20^{9}$ podemos associar a falta de acessibilidade no SIV com a sensação de alheamento e de desvantagem em relação aos usuários que enxergam.

\footnotetext{
${ }^{7}$ Professor emérito da Escola de Arquitetura da Universidade do Estado da Carolina do Norte (NCSU), autor e um dos fundadores do EDRA (Environmental Design Research Association).

${ }^{8} \mathrm{O}$ recorte oi realizado com fins de acomodar a análise aos limites do artigo. A análise de todas as categorias podem ser consultadas na Dissertação intitulada "Acessibilidade nos terminais aeroportuários brasileiros: contradições entre a legislação e a experiência da pessoa com deficiência visual" (CAVALCANTE, 2017).

${ }^{9}$ Os respondentes serão representados pelas siglas $\mathrm{Rn}{ }^{\circ}$, sendo seus nomes ocultados para fins de preservação dos indivíduos.
} 


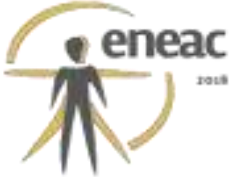

Figura 1 - Saguão do SDU: tela SIV e balcão de informações da Infraero

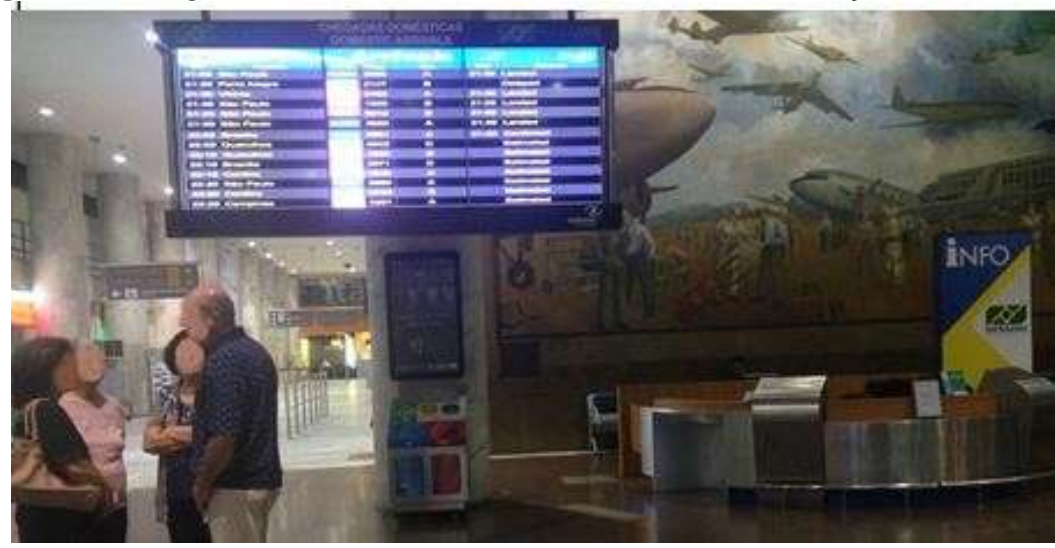

Fonte: Arquivo próprio, 2016.

A Lei no 10.098/2000 estabelece normas gerais e critérios básicos para a promoção da acessibilidade em espaços públicos, inclusive nos meios de transporte. A lei encarrega o poder público de eliminar as barreiras na comunicação e de estabelecer alternativas acessíveis para o uso de sistemas de comunicação e de sinalização pelas pessoas com deficiência sensorial e com dificuldade de comunicação. Vemos que o assunto é abordado de forma genérica e, na prática, é pouco associado aos sistemas aeroportuários.

b) Esteiras de bagagem: sabemos que o uso do sistema é simples para quem enxerga, contudo verificamos que é difícil para a PCDV identificar e retirar a sua bagagem. Como comenta nosso entrevistado com deficiência visual:

Como é que você pode pensar numa acessibilização [sic] da esteira que traz a tua bagagem? Como é que você sabe que a tua bagagem está chegando ou não chegando, se você não estiver ao lado de uma pessoa que diga? (R18)

Todos os nossos respondentes apontaram a opção pelo atendimento assistido como forma de garantir a segurança do passageiro e da bagagem. Não há legislação específica sobre o assunto.

c) Carrinho de bagagem: verificamos que o modelo atualmente utilizado é incompatível com o uso da bengala, não sendo efetivamente utilizado pelas PcDVs, que optam por restringir os volumes transportados. Constatamos que não há legislação pertinente ao assunto no que se refere ao design do carrinho nem do atendimento assistido no percurso entre o desembarque de transporte terrestre (carro, táxi, e outros) e o balcão de informações do terminal.

d) Caixa eletrônico: a NBR no 15250/05, referente à acessibilidade em caixa de autoatendimento bancário, estabelece o desenho universal para tais equipamentos, com autonomia e a segurança. A norma requer dispositivo alternativo para entrada de dados e acionamento de funções através do teclado numérico ou por comandos de voz que substituam a função da tecla virtual. Declara obrigatória a disposição de conectores para fones de ouvido pessoais, bem como a sinalização tátil e visual das teclas, inclusive a diferenciação tátil da tecla " 5 " das demais. Além disso, especifica que deve haver dispositivo sonoro capaz de contemplar todas as informações necessárias para o uso autônomo em qualquer etapa da transação.

Verificamos que há dificuldades no uso das teclas touch screen e das teclas com sinalização em alto relevo pela PcDV, o que frustra a utilização do equipamento. Um de nossos entrevistados asseverou: 


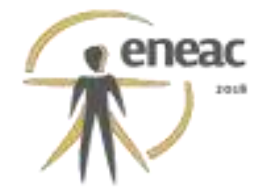

Mesmo que tenha o fone de ouvido ou um programa que fale, de vez em quando eles pedem umas letras a mais, pedem data de aniversário, colocam umas coisas estranhas que, às vezes, não é falado, entendeu? (R20)

Constatamos que, apesar da disponibilização de opções alternativas para os comandos touch screen referidos pelas normas, a utilização, na prática, não condiz com a autonomia pretendida. Conforme exposto pela informante R1, as telas em relevo são pouco indutivas: "[...] Isso aqui é o que? Vezes?! [referente ao símbolo ' $X$ ' em relevo na tecla 'cancela']". A NBR no 15250/05 não contempla os textos "cancela", "corrige" e "entra" em Braille, nem nas teclas e nem em legenda auxiliar. As teclas referentes a tais funções dispõem apenas das marcações "X", "l" e "0" em relevo (Figura 2), sendo de difícil compreensão.

Figura 2 - Teclado de caixas eletrônicos

\begin{tabular}{|c|c|c|}
\hline Tecla & Cor & Marcaçäo \\
\hline CANCELA & Vermelha & $\mathbf{x}$ \\
\hline CORRIGE & Amarela & 1 \\
\hline ENTRA & Verde & $\mathbf{0}$ \\
\hline
\end{tabular}
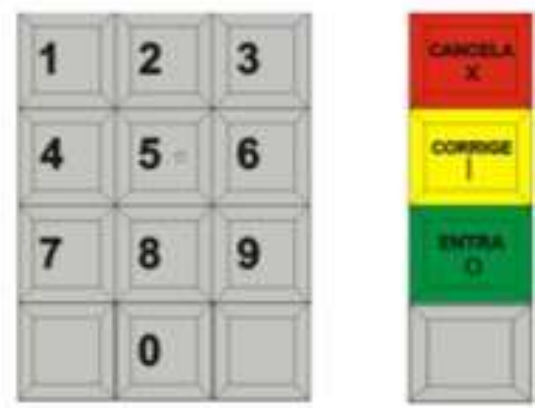

Fonte: ABNT (2005). Nota: Conforme a norma, as teclas "entra", "corrige" e "cancela" devem obedecer a padrões de cores ou inscrições, sendo apenas as marcações exigidas em relevo.

Ademais, constamos o medo do usuário em relação à sua segurança: "O caixa eletrônico eu até evito pelo seguinte: eu não sei quem é que está atrás de mim” (R20). Não há citações normativas ou legais capazes de resguardar a PcDV na fila do equipamento.

e) Telefone público: a NBR no 9050/15 determina que os telefones atendam aos princípios do desenho universal. A Resolução $n^{\circ} 473 / 2007$ da ANATEL especifica que a tecla do dígito "5" deve possuir marcação em relevo que facilite sua identificação. Observamos que os telefones públicos foram utilizados pelos PcDV com desenvoltura graças à tal marcação, parecendo estar a legislação adequada às necessidades da PcDV.

f) Separador de fluxo: verificamos que os modelos utilizados nos terminais são barreiras físicas para a PcDV uma vez que as faixas suspensas não podem ser rastreadas pela bengala. Assim, para a PcDV, além de não cumprir sua função de orientar, ainda potencializa o risco de acidente devido à possibilidade de tropeço e/ou colisão com a haste metálica e/ou a fita, como ilustra a figura 3 e como coloca nosso informante R19: "Aqui é complicado também porque tem esse separador de fluxo. Eu detesto isso. [...]. Porque normalmente a gente esbarra nele." 


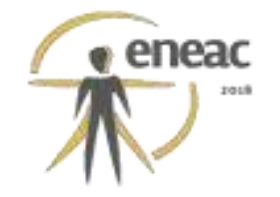

Figura 3 - Separador de fluxo: barreira para as PcDVs

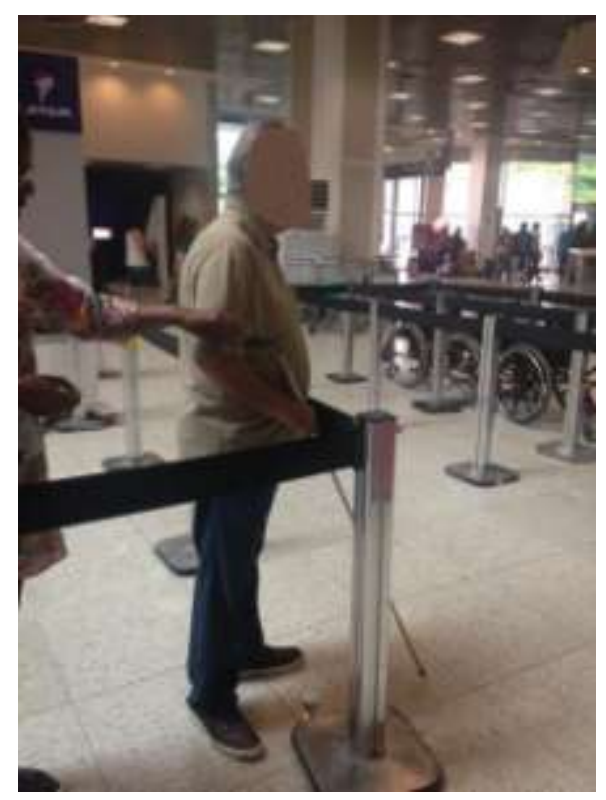

Fonte: Arquivo próprio, 2016.

Embora o caso possa ser analisado com base em outras legislações que, de forma genérica, exigem a acessibilidade em mobiliários e equipamentos ${ }^{10}$ com elementos suspensos, 0 separador de fluxo continua sendo usado inapropriadamente nos terminais do país e do exterior, comprometendo a autonomia e a segurança da PcDV.

g) Bebedouros: alguns usuários consideraram os modelos de bebedouros adotados nos terminais de fácil uso; já outros possuem percepção contrária. As respondentes R20 e R1 exploraram o mesmo modelo de bebedouro. " $E$, seria [fácil usar após tatear um pouco o equipamento]. Eu acabaria descobrindo", constatou R20. Já R1 precisou posicionar o dedo no jato enquanto bebia a água ou abastecia sua garrafa, como forma de identificar sua oscilação, que se mostrava ora mais arqueado, ora menos. Identificamos que nenhuma especificação da NBR n 9050, que trata de bebedouros, é capaz de solucionar a queixa exposta por R1.

Figura 4 - Modelo de bebedouro presente em diversos terminais brasileiros

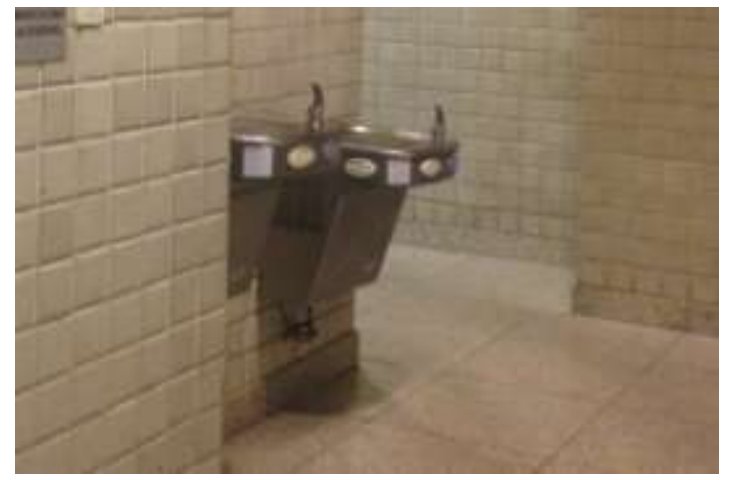

Fonte: Arquivo próprio, 2016.

\footnotetext{
${ }^{10}$ A exemplo da NBR n ${ }^{\circ}$ 9050/15 - Acessibilidade a edificações, mobiliário, espaços e equipamentos urbanos.
} 


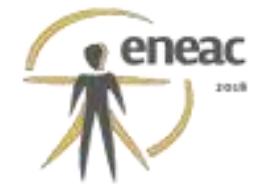

h) Maquinetas de cartões de crédito: é um importante equipamento no usufruto de serviços, varejos e, ainda, em cobranças operacionais (a exemplo de pagamento de excesso de bagagem). Seu uso pela PcDV pode ser impossibilitado caso dispunham apenas de teclados digitais. Nas palavras de nossos informantes:

\begin{abstract}
Atualmente, nós estamos começando a ter uma relação inacessível com algumas lojas e alguns táxis porque eles cobram da gente numa maquininha para cartão... uma maquininha chamada Moderninha, do PagSeguro, que é totalmente inacessível porque ela é tela de toque. (R20)

[...] Você falaria a sua senha do banco em voz alta ao pagar uma compra no cartão de crédito ou débito? É isso que os deficientes visuais precisam fazer ao se deparar com máquinas de cartão sem recursos de acessibilidade, [...]. Com teclado sensível ao toque, esses terminais não possuem nenhum tipo de retorno tátil ou sonoro, dificultando ou impedindo a utilização por pessoas que não enxergam. (BARBATO; ROMEU, 2016).
\end{abstract}

Conforme veiculada pelo jornal Folha de São Paulo (MANTOVANNY, 2016), o problema apontado por nosso respondente persiste. Não há legislação específica para tal questão.

i) Escadas fixas: verificamos que, se acessíveis, apresentam boas condições de uso pela PcDV. Entre outras disposições, a NBR no 9050/15 regulamenta a sinalização e o dimensionamento dos degraus, corrimãos, guarda-corpos e outros. Define que, nas rotas acessíveis, não podem ser utilizados degraus e nem escadas fixas com espelhos vazados, 0 que condiz com a observação de nossos respondentes. Nesse quesito, parece ser a legislação da escada compatível com a experiência da PcDV. Verificamos ainda que a percepção das faixas fotoluminescentes de cor contrastante com o piso nos degraus pelas pessoas de baixa visão depende da boa iluminação do ambiente.

Figura 5 - Técnica de orientação e mobilidade: posicionamento da bengala no degrau da escada
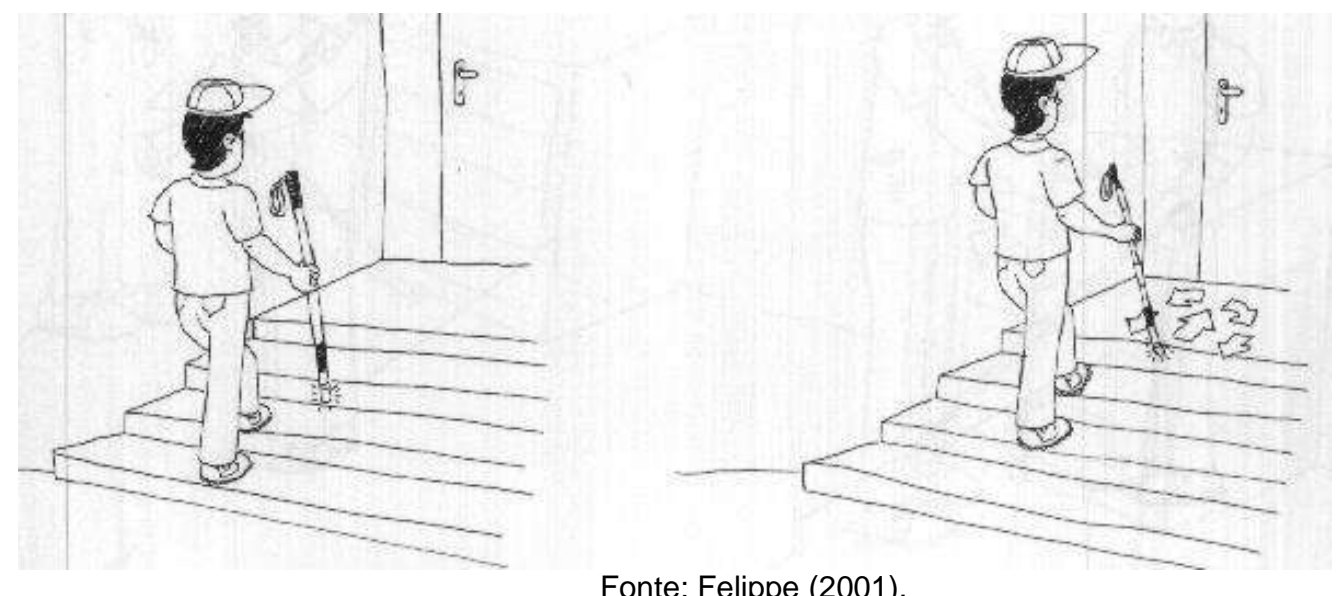

Fonte: Felippe (2001).

j) Equipamentos eletromecânicos de circulação: constatamos que as especificações sobre sinalização de instrução de uso das escadas rolantes (ABNT, 2015) não são atendidas nos terminais. Para os respondentes, contudo, a escada rolante foi considerada boa opção para a circulação vertical. "Escada rolante não é obstáculo, nem escada comum", observou R20.

Quanto ao elevador, verificamos que a indicação tátil no batente é arriscada: para consulta-la é preciso tatear área muito próxima à porta mecânica (ver figura 7). A NBR no 9050 


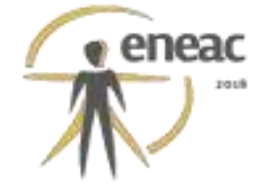

estabelece que "O número do pavimento deve estar localizado nos batentes externos, indicando o andar, em relevo e em Braille, conforme 5.2.8.4, 5.2.8.5 e 5.4.1" (ABNT, 2015, p. 47). À exceção deste quesito verificado como arriscado, a legislação que trata de elevadores, quando aplicada corretamente, tem sido considerada eficaz pela PcDV.

Figura 6- Item 5.4.1 - Sinalização no batente da porta, inclusive em caso de elevadores

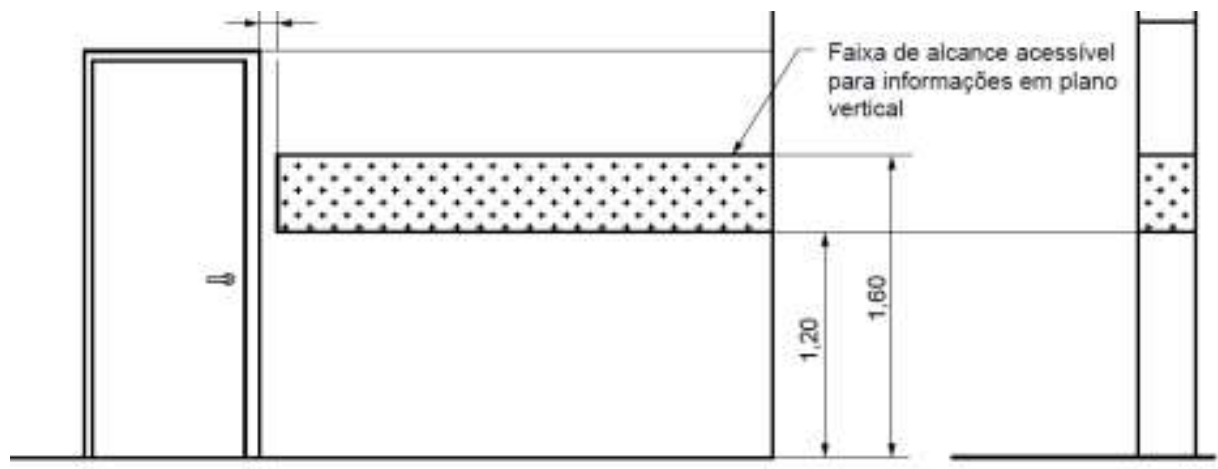

a) Porta

b) Passagem

Fonte: ABNT (2015).

Figura 7 - Sinalização no batente da porta do elevador do terminal do aeroporto de Fortaleza
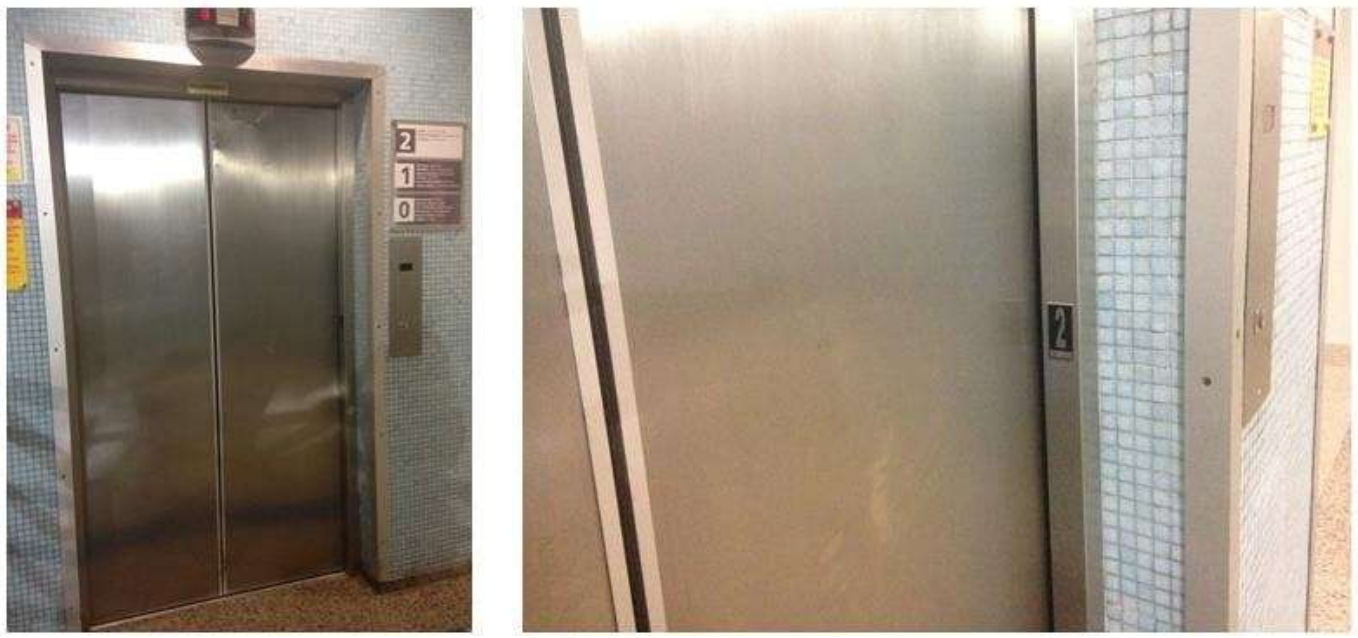

Fonte: Arquivo próprio, 2016.

Nota: À direita, detalhe expondo a proximidade entre a sinalização e a porta mecânica.

A ponte de embarque permite a circulação do passageiro do conector à aeronave. Durante a realização do Simulado de Acessibilidade da Infraero ${ }^{11}$, constatamos que, mesmo assistido, o uso desse equipamento requer atenção. No exercício simulado, havia uma rampa interligando a borda da ponte à porta da aeronave na qual estava acoplada. Quando as PcDVs foram conduzidas em grupo, formando fila diagonal, observamos que a guia adentrou na aeronave seguida pela PcDV que encabeçava a fila, contudo as demais teriam colidido com a lateral da aeronave ou estariam sujeitas a risco devido ao espaçamento no piso não fosse a intervenção

\footnotetext{
${ }^{11}$ O Simulado de Acessibilidade da Infraero aconteceu no SDU em junho de 2015 e teve como objetivos: avaliar os serviços prestados pelos operadores aéreos, aeroportuários e empresas de rampa; verificar a acessibilidade do aeroporto visando melhorar a qualidade dos serviços prestados; aferir e otimizar o tempo necessário para cada procedimento operacional; envolver todas as companhias aéreas e possibilitar o treinamento de suas equipes. Tais informações foram passadas pela Infraero por correio digital às autoras deste trabalho.
} 


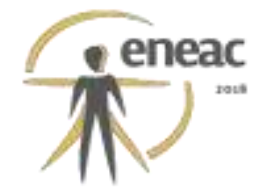

da equipe que acompanhava o simulado. A Legislação que aborda as pontes não trata de tais questões.

Figura 8 - Exercício simulado na ponte de embarque
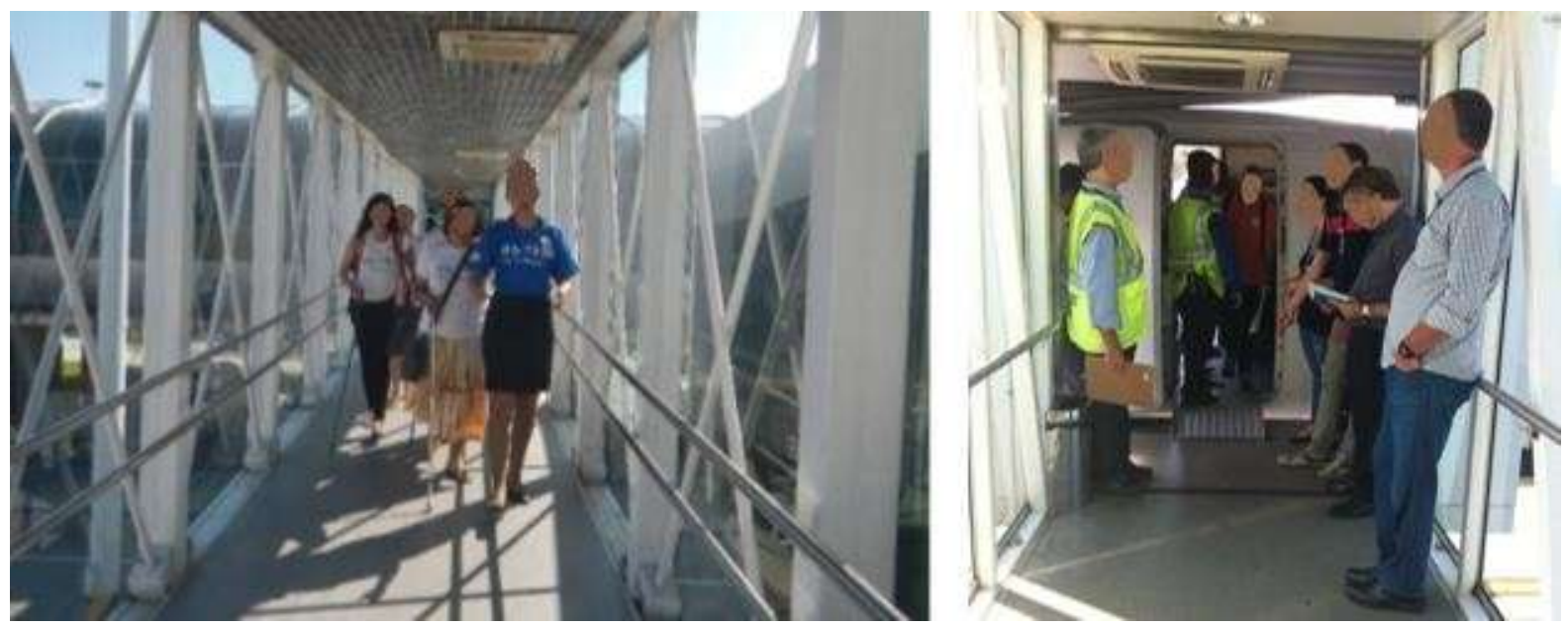

Fonte: Arquivo próprio, 2015.

k) Sanitários: dentre os respondentes, alguns declararam preferir utilizar o sanitário de uso comum, embora a maioria prefira o acessível. O uso exclusivo dos sanitários acessíveis favorece a livre exploração do ambiente por meio da bengala ou do tato, evitando o constrangimento de colidir com outros usuários.

A NBR no 9050 legisla com precisão sobre a instalação de barras e louças sanitárias. Tal padronização costuma ser usada pela PcDV como dica de orientação no ambiente. Os acessórios, contudo, possuem maior flexibilidade quanto a seu posicionamento, devendo respeitar apenas alturas de instalação (faixa de alcance). Sem localização padronizada, mapa tátil do ambiente ou emissão de sons pelos elementos (pistas sonoras), muitos respondentes não utilizam os acessórios (a exemplo de cabides de bolsas), uma vez que não convém tatear toda a extensão das paredes, divisórias ou outros elementos do recinto a sua busca.

Figura 10 - Faixa de alcance de acessórios no lavatório

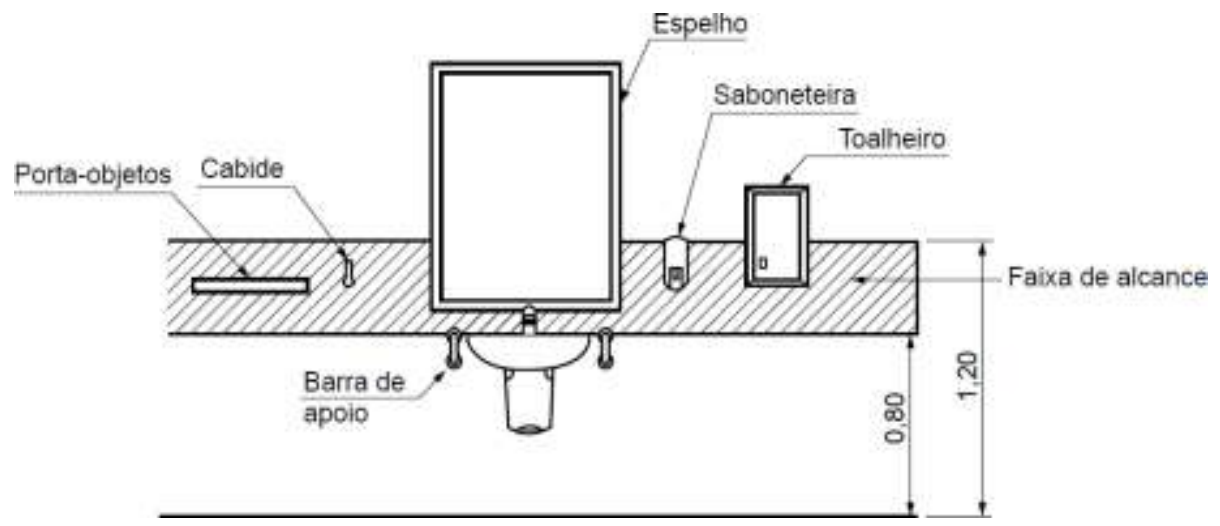

Fonte: ABNT (2015).

Verificamos ainda que os modelos de torneiras com sensor dispostos no SDU e em outros terminais brasileiros possuem área de acionamento restrita. Ao tentar, sem sucesso, utilizar a 


\section{(x) $^{\text {remax }}$}

torneira, R1 exclamou: "Essas torneiras nunca funcionam comigo". Nesse instante, constatamos que suas mãos não estavam alinhadas ao pequeno sensor.

A exploração manual da lixeira é limitada por questões de higiene. Assim, o lixo é arremessado pela PcDV na direção da "boca" da lixeira - a partir da informação obtida pelo rastreamento da base- conforme revela o respondente R20: "Pois é... não, a boca do lixo eu vou tentando! É pontaria...". Se houver tampa ou, ainda, se o design resultar em formatos diferentes na base e na abertura, o lixo arremessado provavelmente não vai entrar.

Como desvantagem do sanitário acessível, foi apontada a espera em filas. Em relação aos de uso comum, as queixas são diversificadas: alguns são vistos como apertados, outros como muito amplos, outros como seccionados ou de difícil orientação, além da já citada dificuldade em explorar o ambiente com a bengala ou mãos. Verificamos que a legislação não apresenta solução para essas dificuldades encontradas pelos usuários com deficiência visual nos sanitários.

I) Balcão de informações: nem no mobiliário nem em sua cercania foram encontradas informações em Braille ou caracteres em relevo, nem equipamentos adaptados para a PcDV.

Além de outros empecilhos à acessibilidade da PcDV no terminal aeroportuário estudado, encontramos, também algumas lacunas legais. Não pudemos deixar de observar a ausência de legislação que regule com detalhes áreas específicas dos terminais aeroportuários como salas de embarque e desembarque, áreas alfandegadas, locais destinados à espera da PcDV, etc. Na forma do Decreto no 5.296/04, cabe aos responsáveis assegurar à pessoa com deficiência espaço para atendimento, assentos preferenciais e áreas especiais para embarque e desembarque. Contudo, faltam especificações sobre as características de tais espaços para a PcDV e para o uso aeroportuário.

\section{CONSIDERAÇÕES SOBRE OS RESULTADOS}

Este artigo buscou demonstrar que o mobiliário, o layout e os equipamentos instalados em um aeroporto considerado acessível nem sempre atendem às expectativas das pessoas com deficiência visual.

A Lei Brasileira de Inclusão da Pessoa com Deficiência (Lei n 13.146/15) determina que "Os veículos de transporte coletivo terrestre, aquaviário e aéreo, [...] e os terminais em operação no país devem ser acessíveis, de forma a garantir o seu uso por todas as pessoas" (BRASIL, 2015, pag. 31). Contudo, a pesquisa que está na base deste artigo demonstrou que o atendimento aos itens preestabelecidos pela legislação e normatizações brasileira não é capaz de dotar os terminais de passageiros contemporâneos de efetiva acessibilidade, ou seja, não garantem uma experiência autônoma e completa para as pessoas com deficiência visual.

A experiência dos usuários, conforme visto na pesquisa, demonstrou o contrassenso existente entre a legislação e a percepção da PcDV. Se, conforme a lei, os resultados parecem animadores a ponto de haver, por exemplo, uma premiação "Diamante" a um terminal, na prática, vimos que os usuários perceberem esses espaços como locais inviáveis em questão de acessibilidade.

Considerando-se as tendências contemporâneas dos aeroportos, acreditamos ser necessário repensar a acessibilidade dentro do novo contexto operacional, comercial e social assumido por estes ambientes. De fato, o usuário do século XXI não se restringe ao passageiro e o uso do terminal não se restringe ao processamento operacional. Apesar da intenção de expansão do público pretendida pelo Aeroshopping e a irreversível consolidação dos terminais quanto a espaços que abrigam funções diversas além das operacionais, como sociais, culturais, artísticas, educacionais, dentre outras, percebe-se a manutenção de políticas rigidamente 


\section{(x) $^{\text {remax }}$}

vinculadas ao passageiro, levando-se em muita pouca consideração os não viajantes.

Nossos informantes nos fizeram compreender que seus direitos e deveres como cidadãos poderão ser atingidos quando lhes for permitido usufruir de todos os serviços oferecidos pelos terminais, e não apenas das funções de embarcar e desembarcar.

O aeroporto é lugar de evasão, de liberdade simbolizada na partida e na chegada, de recomeços e de fechamentos, de conquista dos ares. Frente à grandeza desse simbolismo, é fácil imaginar a sensação que a falta de acessibilidade imprime nas pessoas com deficiência visual: a falta de acessibilidade nesses lugares significa muito mais do que a exclusão em um ambiente construído.

Para que seja efetivada a inclusão, pelo menos no âmbito do ambiente, é necessário que as expectativas do usuário sejam satisfeitas. Para tal, muito mais do que estar limitado às leis e normas vigentes, é preciso continuar buscando, junto com as pessoas com deficiência, soluções para a ainda inadequação do ambiente dos terminais de passageiros.

\section{REFERÊNCIAS BIBLIOGRÁFICAS}

ABNT - ASSOCIAÇÃO BRASILEIRA DE NORMAS TÉCNICAS. NBR 14273: acessibilidade da pessoa portadora de deficiência no transporte aéreo comercial. Rio de Janeiro, 1999.

NBR 13994: elevadores de passageiros. Elevadores para transporte de pessoa portadora de deficiência. Rio de Janeiro, 2000.

NBR 9050: acessibilidade de pessoas portadoras de deficiência a edificações, espaço, mobiliário e equipamentos urbanos. Rio de Janeiro, 2004.

NBR 10634: aeroportos. Ponte de embarque e desembarque para aeronaves. Rio de Janeiro, 2012.

NBR 9050: acessibilidade de pessoas portadoras de deficiência a edificações, espaço, mobiliário e equipamentos urbanos. Rio de Janeiro, 2015.

BARBATO, Renato; ROMEU, Paulo. Pela acessibilidade nas máquinas de pagamento de cartão de crédito. Inclusive - Inclusão e Cidadania, 8 de maio de 2016. Disponível em: <http://www.inclusive.org.br/arquivos/29294>. Acesso em: fev. 2017.

BRASIL. Decreto-lei no 200, de 25 de fevereiro de 1967. Dispõe sobre a organização da Administração Federal, estabelece diretrizes para a Reforma Administrativa e dá outras providências. Brasília: Presidência da República, 1967.

Lei $n^{\circ}$ 5.862, de 12 de dezembro de 1972. Constitui a Empresa Brasileira de Infraestrutura Aeroportuária - Infraero.

Decreto no 5.296, de 2 de dezembro de 2004. Regulamenta as Leis $n^{\circ 5} 10.048$, de 8 de novembro de 2000 , que dá prioridade de atendimento às pessoas que especifica, e 10.098, de 19 de dezembro de 2000 Brasília, DF, 2004. Disponível em:

www.planalto.gov.br/ccivil_03/_ato2004-2006/2004/decreto/d5296.htm. Acesso em: 20 maio 2016.

BRASILEIRO, Alice et al. Avaliação de desempenho das instalações internas do Proarq utilizando wish poem. In: NUTAU'2004 - Demandas sociais, inovações tecnológicas e a cidade, 2004, São Paulo. Anais... São Paulo: Universidade de São Paulo, 2004. 8 p.

CAVALCANTE, Erika. Acessibilidade nos terminais aeroportuários brasileiros: contradições entre a legislação e a experiência da pessoa com deficiência visual. Dissertação (Mestrado em Arquitetura) - Universidade Federal do Rio de Janeiro, Rio de Janeiro, 2017. 


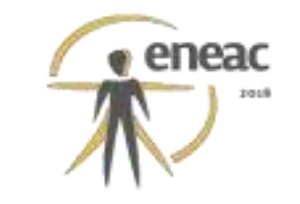

CAVALCANTE, Erika; DUARTE, Cristiane; COHEN, Regina. Arquitetura de aeroportos: dos terminais de passageiros aos aero shoppings. Revista Projetar, v. 2, p. 57-68, 2017. FELIPPE, João Álvaro de Moraes. Apostila Caminhando Juntos. 2001. Disponível em: www.ebah.com.br/content/ABAAAfn7UAL/apostila-caminhando-juntos-por-joao-alvaromoraes-felippe. Acesso em 18 nov. 2016. [on-line].

GODOY, Arilda Schmidt. Introdução à pesquisa qualitativa e suas possibilidades. Revista de Administração de Empresas (RAE), São Paulo, v. 35, n. 2, p. 57-63, mar./abr. 1995. Disponível em: www.scielo.br/pdf/rae/v35n2/a08v35n2.pdf . Acesso em: 5 maio 2016.

MANTOVANNY, Kelly. Máquina de cartão sem tecla limita uso de deficiente visual. Folha de São Paulo, 19 de setembro de 2016. Disponível em: www1.folha.uol.com.br/mercado/2016/09/1814412-maquina-de-cartao-sem-tecla-limita-usopor-deficiente-visual.shtml_. Acesso em: fev. 2017.

VENTORINI, Silvia Elena. A experiência como fator determinante na representação espacial do deficiente visual. São Paulo: Unesp, 2009.

YOUNG, Seth; WELLS, Alexander. Aeroportos: planejamento e gestão. Tradução de Ronald Saraiva de Menezes. 6. ed. Porto Alegre: Bookman, 2014. 